\title{
Success is the Sum of Small Efforts!
}

\author{
Atul P Kulkarni ${ }^{1}$, Srinivas Samavedam², Ashit Hegde ${ }^{3}$ \\ Indian Journal of Critical Care Medicine (2019): 10.5005/jp-journals-10071-23245
}

Big things have small beginnings!

-Prometheus

It is with great joy that we present to you, the second issue of Frontiers in Critical Care Medicine, the special issue of Indian Journal of Critical Care Medicine. We have received an excellent feedback about the first issue of the Frontiers in Neurocritical Care. Dr Srinivas Samavedam and Dr Hegade must be congratulated for their hard work in putting this issue together. We hope that this issue will be equally popular among our readers.

Transfusion of blood and its components is one of the most common interventions in the critically ill patients. The ICON study found that the mean lowest admission hemoglobin was $10.7 \pm 2.4$ $\mathrm{g} / \mathrm{dL}$; while more than $25 \%$ patients had hemoglobin concentration lower than $9 \mathrm{~g} / \mathrm{dL}$. Patients transfused during ICU stay had higher ICU and hospital mortality ( $21.5 \%$ vs $14.3 \%$ and $30.0 \%$ vs $19.6 \%$, both $p<0.001)$. In sicker (admission SOFA >8), higher SAPS II (52-119), medical and anemic patients, however, transfusion was associated with lower likelihood of death. The chances of survival increased step-wise with transfusion, in patients with increasing admission severity scores.

A recent worldwide survey reported that the transfusion threshold for RBCs transfusion was $7 \mathrm{~g} / \mathrm{dL}$ in general critically ill patients, while it ranged between $7 \mathrm{~g} / \mathrm{dL}$ and $9 \mathrm{~g} / \mathrm{dL}$ in patients with brain injury and those undergoing extracorporeal membrane oxygenation. ${ }^{2}$ Only one third of respondents used ICU specific guidelines for transfusion blood and blood products. The transfusion threshold for patients with acute coronary syndrome was highest at $9 \mathrm{~g} / \mathrm{dL}$. The threshold for transfusion of platelets was $20 \times 10^{9}$, (being higher if invasive procedure was planned); while around $50 \%$ respondents would infuse FFP if the INR was 3 or greater, if there was an intervention planned.

Various coagulation disorders are seen in critically ill and trauma patients, acute traumatic coagulopathy and disseminated intravascular coagulation, being the most common disorders. ${ }^{3} \mathrm{~A}$ variety of tests have now become available to diagnose coagulation disorders. ${ }^{4}$

In this issue, we deal with discussions ranging from physiology of oxygen transport, various tests used for diagnosis and management of coagulation disorders, to topics such as auditing
${ }^{1}$ Division of Critical Care Medicine, Department of Anesthesiology, Critical Care and Pain, Tata Memorial Hospital, Homi Bhabha National Institute, Mumbai, Maharashtra, India

${ }^{2}$ Department of Critical Care, Virinchi Hospitals, Hyderabad, Telangana, India

${ }^{3}$ Department of Critical Care and Medicine, PD Hinduja National Hospital and Medical Research Centre, Mumbai, Maharashtra, India

Corresponding Author: Atul P Kulkarni, Division of Critical Care Medicine, Department of Anesthesiology, Critical Care and Pain, Tata Memorial Hospital, Homi Bhabha National Institute, Mumbai, Maharashtra, India, e-mail: kaivalyaak@yahoo.co.in

How to cite this article: Kulkarni AP, Samavedam S, Hegde A. Success is the Sum of Small Efforts! Indian J Crit Care Med 2019;23(Suppl 3):S171. Source of support: Nil

Conflict of interest: None

transfusion practice, guidelines for infusion of blood products, etc. We have also included one article on landmark trials in transfusion in critically ill and an article on statistics. There are articles on pointof-care testing for coagulation to hemostatic agents used in the ICU. We hope you enjoy reading this issue, as much as we enjoyed putting it together.

Happy reading!

\section{References}

1. Vincent JL, Jaschinski U, Wittebole X, Lefrant JY, Jakob SM, Almekhlafi $\mathrm{GA}$, et al; ICON Investigators. Worldwide audit of blood transfusion practice in critically ill patients. Crit Care. 2018;22(1):102.

2. de Bruin S, Scheeren TWL, Bakker J, van Bruggen R, Vlaar APJ; Cardiovascular Dynamics Section and Transfusion Guideline Task Force of the ESICM. Transfusion practice in the non-bleeding critically ill: an international online survey-the TRACE survey. Crit Care. 2019; 23(1):309.

3. Gulati D, Novak A, Stanworth SJ. Common haemostasis issues in major bleeding and critical illness. Clin Med (Lond). 2018;18(4):320-323.

4. Favaloro EJ, Lippi G. Recent Advances in Mainstream Hemostasis Diagnostics and Coagulation Testing. Semin Thromb Hemost. 2019; 45(3):228-246.

(0) The Author(s). 2019 Open Access This article is distributed under the terms of the Creative Commons Attribution 4.0 International License (https://creativecommons. org/licenses/by-nc/4.0/), which permits unrestricted use, distribution, and non-commercial reproduction in any medium, provided you give appropriate credit to the original author(s) and the source, provide a link to the Creative Commons license, and indicate if changes were made. The Creative Commons Public Domain Dedication waiver (http://creativecommons.org/publicdomain/zero/1.0/) applies to the data made available in this article, unless otherwise stated. 